\title{
First species of Laselva Furth from Brazil (Chrysomelidae: Galerucinae: Alticini)
}

\author{
Tarcila Rech ${ }^{1}$ \& Adelita Maria Linzmeier ${ }^{2}$ \\ 1 Universidade Federal da Grande Dourados (UFGD), Programa de Pós-Graduação em Entomologia e Conservação da Biodiversidade. \\ Dourados, MS, Brasil. ORCID: http://orcid.org/0000-0001-8362-3518. E-mail: tarcilarech@gmail.com \\ ${ }^{2}$ Universidade Federal da Fronteira Sul (UFFS). Realeza, PR, Brasil. ORCID: http://orcid.org/0000-0002-2979-8728. \\ E-mail: adelita.linzmeier@uffs.edu.br
}

\begin{abstract}
Laselva cleidae sp. nov., the first species of Laselva Furth, 2007 found in Brazil is described and illustrated. Species of Laselva are compared with those of Deciplatus Linzmeier \& Konstantinov, 2009 and Andersonaltica Linzmeier \& Konstantinov, 2012. This is the first species of Laselva recorded to South America.
\end{abstract}

Key-Words. Paraná; Taxonomy; Neotropical Region; New species; Flea beetles.

\section{INTRODUCTION}

Alticini (Chrysomelidae: Galerucinae) is a group of highly specialized phytophagous insects with 9,990 valid species assigned in 577 valid genera (Konstantinov, 2016). The subtribe Monoplatina Chapuis, 1875 currently comprises 48 genera, with more than 575 species distributed mainly in the Neotropical region, most of them in South America (Linzmeier \& Konstantinov, 2018) with 27 genera and 223 species registered to Brazil (Clark, 1860; Scherer, 1983; CTFB, 2019). Laselva Furth, 2007 is a monotypic genus described from Atlantic tropical rainforest of Costa Rica. In this study a discovery of a new species of Laselva in Brazil is documented, the first record to South America. This new species is the result of an inventory developed in forest remnants of southwest of state of Paraná, a region highly impacted by agribusiness, whose biological diversity has been insufficiently studied (Oliveira et al., 2019). Nevertheless, the discovery of a new species highlights the importance of forest remnants and studies of their biodiversity.

\section{MATERIAL AND METHODS}

Adults were sampled by the Project "Diversidade de Alticini em Fragmentos Florestais no Sudoeste do Paraná" with malaise traps in two forest fragments of Atlantic forest, in a transitional region between Montana and Submontana Araucaria mixed Forest. Characters of external morphology and female genitalia were examined, since only females were collected. Dissecting techniques, measurements and terminology follows Konstantinov (1998). As the specimens were sampled with malaise traps, biological data was not available.

Label descriptions from holotype and paratypes are organized from top to bottom with each label separated by a bar (/). The data of each line for each label is separated by semicolon. All information from each labels is listed verbatim with added details enclosed by square brackets ([ ]) and, gender and depositories are included between parenthesis.

The specimens will be deposited in Coleção Entomológica Pe. J.S. Moure, Departamento de Zoologia, Universidade Federal do Paraná, Curitiba, Brazil (DZUP) and Coleção Entomológica do Laboratório de Zoologia, Universidade Federal da Fronteira Sul, campus Realeza, Paraná (UFFS-RE).

\section{RESULTS}

\section{Laselva cleidae sp. nov.}

(Figs. 1 A-E, 2 A)

Type material: Holotype, \& (DZUP): Labels: Realeza, Paraná, Brasil; 2547'22.1"S, 53³1'30.4"W, 514 m; 26.X.2017, malaise 4; Rech, T., col./ Holotype Laselva cleidae Rech \& Linzmeier, 2020 [redlabel]. Paratypes: Planalto, Paraná, Brasil; 2547'05.4"S, 5338'43.5"W, 388 m; 28.X.2017, malaise 6; Linzmeier, A.M., col./ Paratype Laselva cleidae Rech \& Linzmeier, 2020 [yellowla- 
bel] (19 DZUP). Planalto, Paraná, Brasil; 2547'05.4"S, 53³8'43.5"W, 388 m; 25.XI.2017, malaise 6; Linzmeier, A.M., col./ Paratype Laselva cleidae Rech \& Linzmeier, 2020 [yellowlabel] (19 DZUP). Realeza, Paraná, Brasil; 254'25.5"S, 5331'31.2"W, 492 m; 18.XI.2016, malaise 5; Oliveira, D.W.G., col./ Paratype Laselva cleidae Rech \& Linzmeier, 2020 [yellowlabel] (19 DZUP). Realeza, Paraná, Brasil; 2547'22.1"S, 53³1'30.4"W, 514 m; 04.X.2017, malaise 4; Morais \& Oliveira, col./ Paratype Laselva cleidae Rech \& Linzmeier, 2020 [yellowlabel] (19 DZUP).

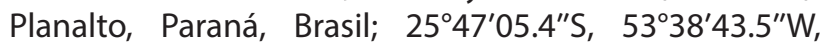
388 m; 12.XI.2017, malaise 6; Linzmeier, A.M., col./ Paratype Laselva cleidae Rech \& Linzmeier, 2020 [yellow label] (19 DZUP). Planalto, Paraná, Brasil; 2547'06.0"S, 53³8'43.6"W, 395 m; 23.X.2016, malaise 3; Linzmeier, A.M., col./ Paratype Laselva cleidae Rech \& Linzmeier, 2020 [yellowlabel] (19 UFFS-RE). Planalto, Paraná, Brasil; $25^{\circ} 47^{\prime} 05.4^{\prime \prime} \mathrm{S}, 53^{\circ} 38^{\prime} 43.5^{\prime \prime} \mathrm{W}, 388 \mathrm{~m}$; 14.X.2017, malaise 6; Linzmeier, A.M., col./ Paratype Laselva cleidae Rech \& Linzmeier, 2020 [yellowlabel] (19 UFFS-RE).

Diagnosis: Laselva cleidae sp. nov., is distinguished from L. triplehorni Furth, 2007 by having (L. triplehorni in parenthesis) the antennal callus indistinguishable (antennal callus distinct); frontal and anterofrontal carina forming a single triangular structure, with lateral margins raised and slightly bent outward (carina not evident) (Fig. 2); antennomere IV of female smallest (antennomere VI smallest); setae present on anterior and posterior angles of pronotum (only on anterior angles); and metatarsus with visible tarsomere IV smooth (rugose).

Description: Body length: $2.7 \mathrm{~mm}$, width $1.5 \mathrm{~mm}$ (Figs. 1A-B). Body dark brown, shinny; seven basal antennomeres and tibiae light brown; venter and femora reddish brown. Dorsum (head, pronotum, elytra) punctured, covered with stout, long and golden pubescence, one seta associated with each puncture.

Head: Hypognathous, slightly convex in lateral view (Fig. 1B). Frons and vertex entirely covered with dense coarse punctures, with golden pubescence. Antennal calli and supraorbital pores indistinguishable. Eyes large, elongated, inner margin straight. Interocular distance subequal to maximum eye length. Frontal and anterofrontal carinae forming a single triangular structure, punctured as vertex, with lateral margins raised and slightly bent outward, merged medially above antennal insertion, forming a short central carina. Supraantennal and frontolateral sulci deep. Labrum notched at middle, with four setiferous pores, lateral margins rounded (Fig. 2A).

Antenna (Fig. 1C) with 11 antennomeres, short, extending to elytral base; all antennomeres bearing long, thickened and black setae; antennomeres I to VII light brown, VIII to XI dark brown and densely covered with short setae; antennomere I longer, cylindrical; antennomere II with half length of antennomere I; antennomere III thinnest; antennomere IV the smallest; antennomeres V and VI similar in length, slightly longer than IV; anten- nomeres VII to X slightly longer and wider than Vl; antennomere XI conical.

Pronotum (Fig. 1D): Dark brown, punctured, pubescent, tegument reticulated, rectangular, $2.3 \times$ wider than long; anterior margin straight, posterior margin slightly sinuous; lateral margins subparallel, anterior angles beveled, slightly pointed outward on lateral margins; setiferous pore present, located on lateral margin, with a long seta; posterior angles projected outward, bearing a seta shorter than anterior ones. Antebasal impression absent; pronotal disc slightly raised. Scutellum triangular, pubescent. Prosternal surface rough; prosternal intercoxal process as wide as prosternum, extended and widened posteriorly beyond procoxa, ending in a triangular shape. Procoxal cavity open posteriorly. Mesosternum similar in length of prosternum but slightly wider. Metasternum smooth and pubescent, convex in lateral view, as long as pro- and mesosterna together.

Elytron (Fig. 1A): Dark brown, elytral surface shiny and punctured, with punctures forming nine striae (not counting marginal and short justascutellar striae), each puncture with a golden seta recumbent posteriorly; dark, erect setae inserted on interstrial space; basal and humeral calli well developed; impression between basal and humeral calli ending deeper behind basal callus; epipleura sinuous extending whole length of elytra ending subapically, laterally bent inward.

Legs: Pro- and mesofemora subcylindrical; pro- and mesotibiae parallel in dorsal view, slightly wider towards apex (in lateral view), pubescence sparsely distributed. Pro- and mesotarsi with tarsomere I slightly longer than tarsomere II; tarsomere II as long as tarsomere III; tarsomere III bilobed; visible tarsomere IV slightly longer than tarsomere I. Pro- and mesotarsal claws appendiculate. Metafemur greatly enlarged, about 1.5 times longer than wide, longer than metatibia, pubescent. Metatibia (Fig. 1E) straight in lateral view, slightly curved in dorsal view, extending beyond tarsal insertion, marginate dorsally, with sulcus between the dorsal margins; apex of inner and outer dorsal margins with denticles; metatibial apex bearing a short spur. Metatarsus with tarsomere I longest; tarsomere II half the length of tarsomere I; tarsomere III shortest, not bilobed; visible tarsomere IV slightly shorter than tarsomeres II and III joined, globose, smooth. Metatarsal claws appendiculate.

Abdomen: Shiny, pubescent, with five visible ventrites. Female genitalia similar to $L$. triplehorni.

Etymology: The specific epithet is in honor of Dr. Cleide Costa, on the occasion of her $80^{\text {th }}$ birthday, for dedicating her career to the study of Coleoptera.

Geographical distribution: Southwest Paraná, Brazil.

Remarks: Species of Laselva and Andersonaltica Linzmeier \& Konstantinov, 2012 share the shiny elytral 


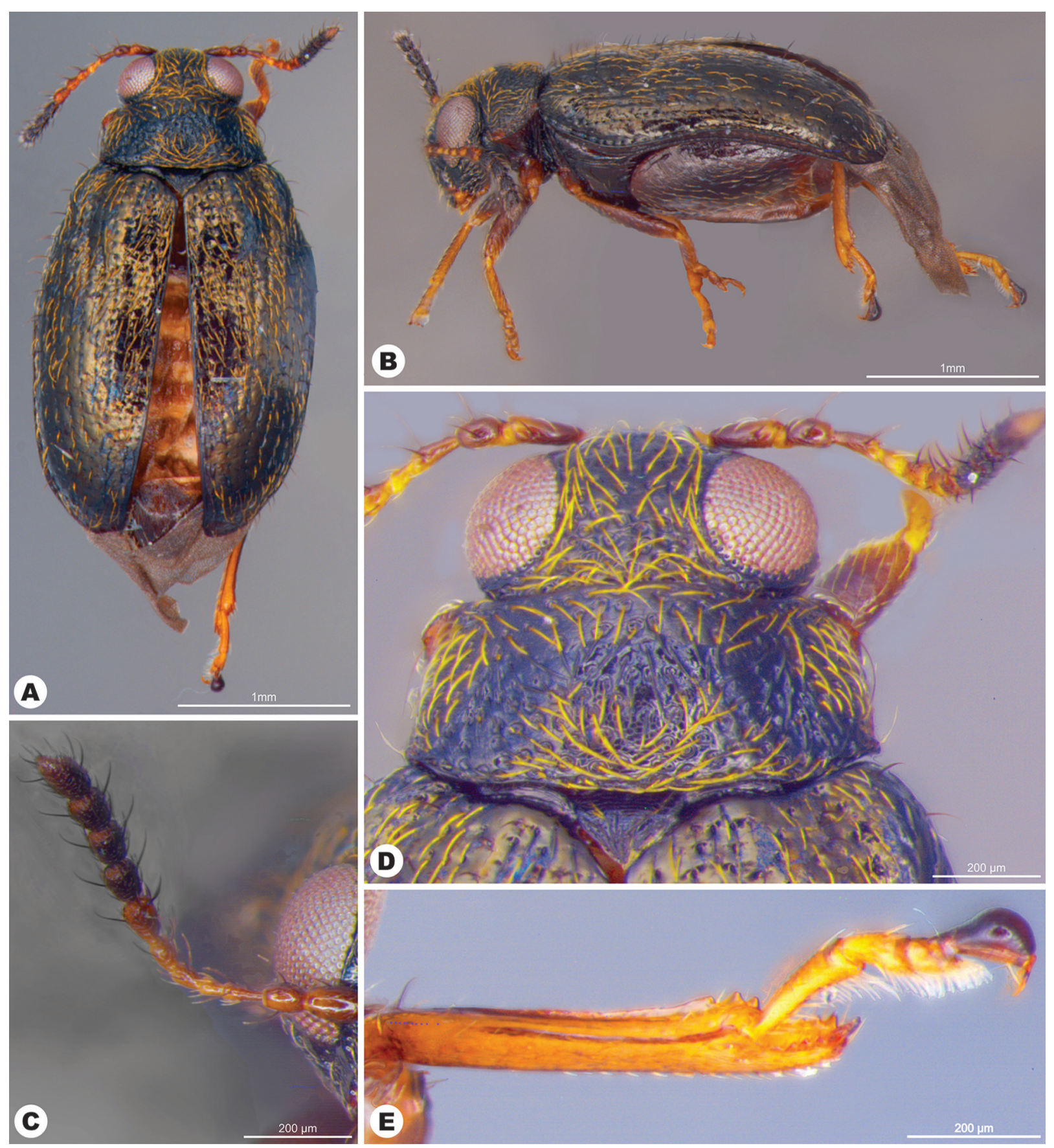

Figure 1. Laselva cleidae sp. nov. Holotype female: (A) dorsal habitus; (B) lateral habitus; (C) antenna; (D) pronotum; (E) metatibia and tarsus.
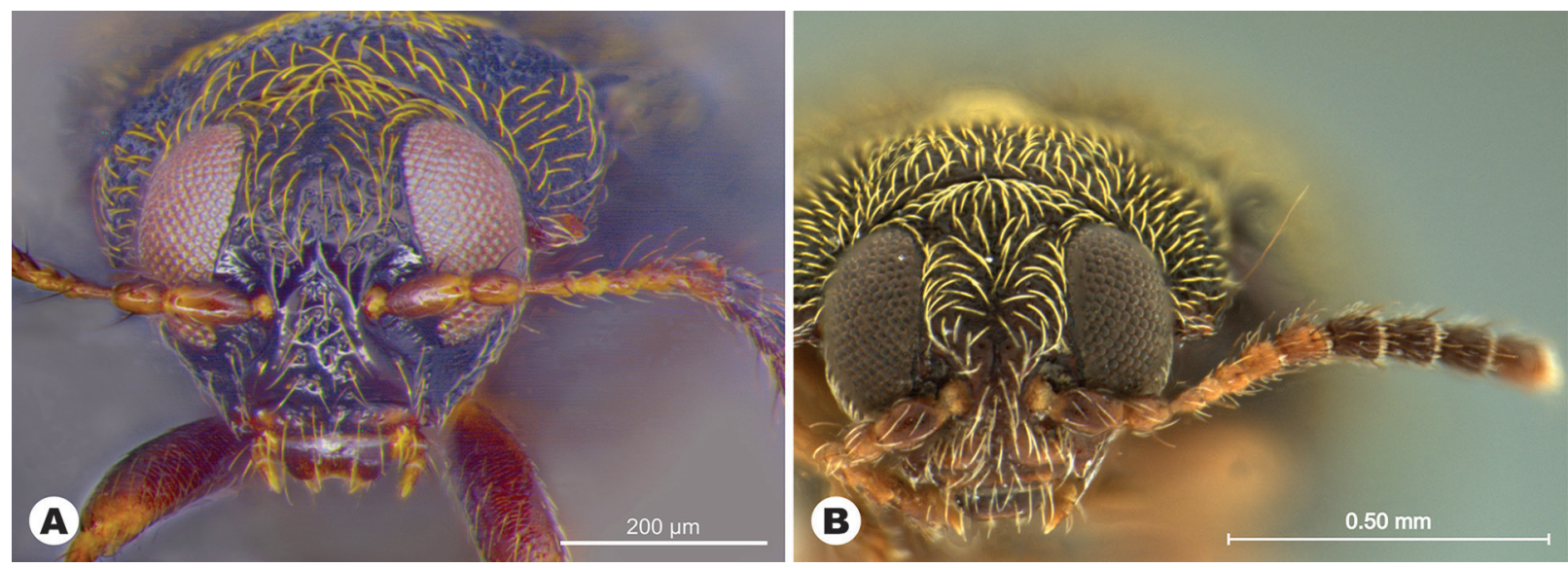

Figure 2. Head, frontal: (A) Laselva cleidae sp. nov.; (B) Laselva triplehorni Furth, 2007. 
surface, punctures forming nine striae, and absence of pronotal antebasal transverse impression. They are differentiated by having (Andersonaltica in parenthesis) antennal calli indistinguishable (antennal calli small, generally nearly indistinguishable), antenna filiform (antenna forming a tight club), humeral calli well developed (humeral calli absent or poorly developed), posterior wings present (apterous) and procoxal cavities open posteriorly (procoxal cavities closed posteriorly).

Among the Monoplatina genera, Laselva species are very similar to those of Deciplatus Linzmeier \& Konstantinov, 2009. They share similar body size, proportions of pronotum, pubescence on elytra, procoxal cavity opened posteriorly and metatarsus inserted subapically. These genera can be easily differentiated by the number of antennomers, 11 in Laselva and 10 in Deciplatus. Surprisingly, some of the main features that separate L. cleidae sp. nov., from L. triplehorni, such as the shape of the anterofrontal and frontal carina and the antenal callus indistinguishable, besides the female genitalia, are very similar among L. cleidae sp. nov., and Deciplatus species. The female genitalia of $L$. triplehorni and $L$. cleidae sp. nov., are identical, not being an important character to differentiate them. In a recent study, Furth (2019) pointed out that he could not use the male and female genitalia to separate two Cerichrestus Clark, 1860 species because he did not find enough morphological differences. This genus also belongs to Monoplatina and, as mentionated in Furth's paper, other researcher had the same experience studying this group. Apparently, in Monoplatina male and female genitalia do not provide informative taxonomic characters.

Since Chapuis (1875), procoxal cavities, whether opened or closed, have been suggested as a character to separate Oedyonichina (opened posteriorly) from Monoplatina (closed posteriorily). Besides, other caracteristics used to define Monoplatina are punctured-striate elytra and the globosely swollen visible on tarsomere IV of metatarsus (Scherer, 1983; Linzmeier \& Konstantinov, 2012), this last characteristic also shared with Oedyonichina species. However, Laselva and Deciplatus have the procoxal cavities opened posteriorly and were included in Monoplatina by Furth (2007) and Linzmeier \& Konstantinov (2009). Currently, it is unclear if this character changed in some Monoplatina genera or if these two genera do not belong to this taxon. As Monoplatina is very diverse, poorly studied and no phylogenetic studies exist, this issue, as well as evolutionary history of Monoplatina, may be resolved based on a comprehensive phylogentic study.

\section{ACKNOWLEDGMENTS}

We are grateful to Dr. D. Furth and Dr. A.S. Kosntantinov (U.S. National Museum of Natural History) for the access to images of paratypes of L. triplehorni and suggestions on manuscript; to Taxonline - Rede Paranaense de Coleções Biológicas (Universidade Federal do Paraná) for the images of the new species; the first author was supported by Coordenação de Aperfeiçoamento de Pessoal de Nível Superior (CAPES) (№ 88882.457426/2019-01).

\section{REFERENCES}

Catálogo Taxonômico da Fauna do Brasil (CTFB). 2019. Insecta. PNUD. Available at: http://fauna.jbri.gov.br/fauna/faunadobrasil//59. Access in: 17/12/2019.

Chapuis, F. 1875. Famillle des Phytophages. In: Lacordaire, M.M.T. \& Chapuis, F. Histoire Naturelle des Insectes. Genera des Coléoptères ou Exposé Méthodique et critique de tous les genres proposés jusqu'ici dans cet ordre d'insectes. Famille des phytophages. Paris, Roret. v. 11, 420p.

Clark, H. 1860. Catalogue of Halticinae in the collection of the British Museum, part 1. London. 301p.

Furth, D.G. 2007. A new genus and species of flea beetle (Coleoptera: (hrysomelidae: Alticinae) from the rainforest canopy in Costa Rica. Proceedings of the Entomological Society of Washington, 109(1): 90-101.

Furth, D.G. 2019. A new species of the Neotropical mimetic genus Cerichrestus Clark from Costa Rica (Coleoptera: Chrysomelidae: Alticinae): An example of how unknown is biodiversity. Israel Journal of Entomology, 49(2): 179-194.

Konstantinov, A.S. 1998. Revision of the Palearctic species of Aphthona Chevrolat and cladistic classification of the Aphthonini Coleoptera: (hrysomelidae: Alticinae). Memoirs on Entomology International, 11: 1-429.

Konstantinov, A.S. 2016. Possible living fossil in Bolivia: A new genus of flea beetles with modified hind legs (Coleoptera, Chrysomelidae, Galerucinae, Alticini). ZooKeys, 592: 103-120.

Linzmeier, A.M. \& Konstantinov, A.S. 2009. A new genus of flea beetles (Coleoptera: Chrysomelidae) from the south of Brazil. Proceedings of the Entomological Society of Washington, 111(3): 656-665.

Linzmeier, A.M. \& Konstantinov, A.S. 2012. A new genus of leaf litter inhabiting Neotropical Monoplatina (Coleoptera: Chrysomelidae: Galerucinae: Alticini). Zootaxa, 3260: 19-32.

Linzmeier, A.M. \& Konstantinov, A.S. 2018. Andersonoplatus, a new, remarkable leaf litter inhabiting genus of Monoplatina (Coleoptera, Chrysomelidae, Galerucinae, Alticini). ZooKeys, 744: 79-138.

Oliveira, U.; Soares-Filho, B.S.; Santos, A.J.; Paglia, A.P.; Brescovit, A.D.; Carvalho, C.J.B.; Silva, D.P.; Rezende, D.T.; Leite, F.S.F.; Batista, J.A.N.; Barbosa, J.P.P.P.; Stehmann, J.R.; Ascher, J.S.; Vasconcelos, M.F.; Marco, P.D.; Löwenberg-Neto, P. \& Ferro, V.G. 2019. Modelling highly biodiverse areas in Brazil. Scientific reports, 9(6355): 1-9.

Scherer, G. 1983. Diagnostic key for the Neotropical alticine genera (Coleoptera: Chrysomelidae: Alticinae). Entomologische ArbeitenMuseum G. Frey, 31/32: 1-89. 